\title{
Analysis and Design of the Integrated Controller for Precise Motion Systems
}

\author{
Syh-Shiuh Yeh and Pau-Lo Hsu, Member, IEEE
}

\begin{abstract}
Recently, feedforward controllers like zero phase error tracking controllers (ZPETC's) and cross-coupled controllers (CCC's) have been developed to effectively reduce tracking error and contouring error, respectively. This paper proposes an integrated controller which combines ZPETC and CCC to achieve both tracking and contouring accuracy. Furthermore, studies indicate that ZPETC and CCC can be designed separately in the present integrated control design. In the provided experimental setup with a servo table, an optimal ZPETC and a robust $\mathrm{CCC}$ based on the contouring error transfer function (CETF) were designed to achieve desirable frequency responses and stability. Experimental results show that the proposed integrated controller renders significantly improved accuracy in both tracking and contouring.
\end{abstract}

Index Terms - CCC, contouring error, integrated controller, motion systems, optimal feedforward controller, robust controllers, tracking error, ZPETC.

\section{INTRODUCTION}

$\mathbf{I}$ $\mathrm{N}$ real applications, due to the inherent problems of servo lag, friction, backlash, and other difficulties, [1] much effort has recently focused on improving motion accuracy by using various control strategies [2]-[9]. In multiple-axis motion systems, feedback controllers are usually designed independently for each axis and each axial servomechanism tracks input commands to reduce tracking error. In addition to the control design in a feedback loop, feedforward controllers have been widely studied in motion systems to greatly improve tracking accuracy. For example, the zero phase error tracking control (ZPETC) proposed by Tomizuka [10], its modified version [11]-[14], and the optimal ZPETC [15]-[20] effectively reduce tracking error. However, due to physical constraints and modeling error, such improvements in tracking accuracy by applying feedforward controllers are inherently limited.

In addition to tracking accuracy, contouring accuracy is also crucial for a precise motion system as shown in Fig. 1. Since feedforward controllers, which are mainly designed for the minimization of tracking error, reduce contouring error to just a certain extent, contouring accuracy in advanced motion systems should be further improved by applying a more appropriate controller design. The cross-coupled controller (CCC) was proposed by Koren [21] and several modified CCC's

Manuscript received November 18, 1997; revised November 14, 1998. Recommended by Associate Editor, M. Bodson. This work was supported by the National Science Council, Republic of China, under Contract NSC 84-2512-S-009-006.

The authors are with the Department of Electrical and Control Engineering, National Chiao Tung University, Hsinchu 300, Taiwan, R.O.C.

Publisher Item Identifier S 1063-6536(99)08546-2.

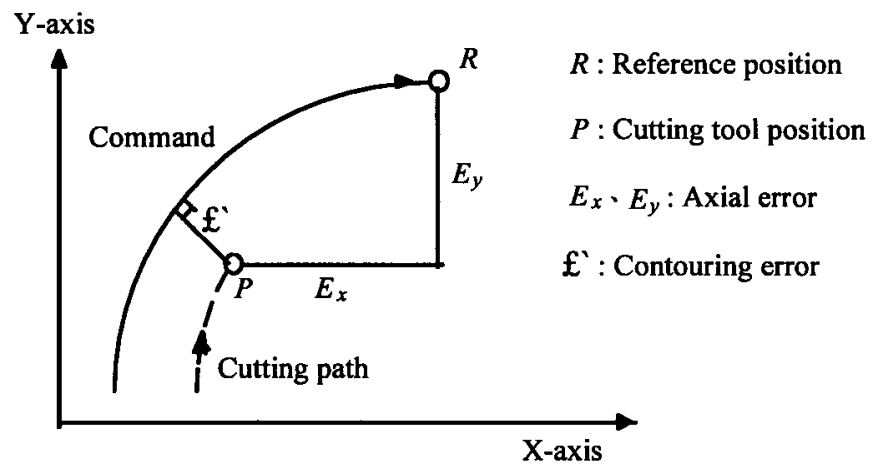

Fig. 1. Tracking and contouring error.

were later developed to further reduce contouring errors [6], [22]-[28]. Basically, by applying the position error adjustment to each axis, the CCC substantially improves the contouring accuracy of multiaxis systems. Recently, theoretical analysis by Yeh and Hsu for CCC systems has achieved guaranteed stability and motion accuracy [29]. Note that although the $\mathrm{CCC}$ has been verified to reduce contouring error, it cannot effectively reduce tracking error.

In industrial applications, most manufacturing systems like the conputerized numerical control (CNC) machines emphasize contouring accuracy which determines product quality. Recently, in many nonconventional manufacturing processes such as laser cutting, laser welding, and electric discharge machining (EDM), etc., contouring velocity in uniformity also directly contributes to the quality of the machining processes. In fact, maintaining precision in both the contouring path and its velocity cannot be achieved by simply implementing a single controller. Since both the velocity and position commands are generated by the interpolator in a motion control system, a good tracking system also guarantees the accuracy of both the contouring velocity and contouring path. Therefore, both contouring error and tracking error need to be minimized simultaneously in precise motion control. Hsu and Houng [30] intuitively integrated a well-tuned CCC and a ZPETC to construct a basic integrated motion control system that both the contouring error and the tracking error were reduced. However, there are unknown coupling effects of the integrated system between the ZPETC and the CCC; thus, systematic design procedures to achieve desirable stability and performance are required.

This paper proposes the contouring error transfer function (CETF) for integrated motion systems. An important finding of the integrated controller design is that the feedforward and the 


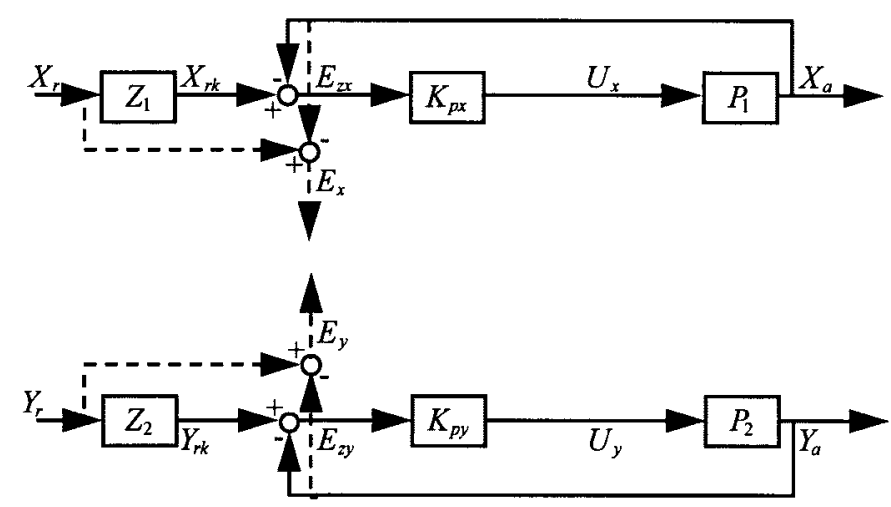

Fig. 2. Motion systems with two independent control axes in a 2-DOF control structure.

CCC controllers can be designed independently. Furthermore, the optimal design for the ZPETC and the robust design for the $\mathrm{CCC}$ in the present integrated controller provide the guaranteed frequency responses and stability. Experimental results on a servo table show that both tracking and contouring errors are significantly reduced by applying the proposed integrated controller.

\section{Motion SyStem ERROR ANALYSIS}

In general, the 1 degree-of-freedom (DOF) control system structure is used in most motion systems and tracking accuracy can be improved with a suitable position controller design. However, control in the 2-DOF structure usually achieves better tracking accuracy [13] and it is considered in some advanced motion control designs, as shown in Fig. 2.

\section{A. Tracking Error}

In Fig. 2, $\left(K_{p x}, K_{p y}\right)$ are position controllers, usually with proportional gains, for each axis. $\left(P_{1}, P_{2}\right)$ are controlled plants and $\left(Z_{1}, Z_{2}\right)$ are feedforward controllers for each axis. Signals $\left(X_{r}, Y_{r}\right)$ and $\left(X_{a}, Y_{a}\right)$ are the reference input and output signals of the system, respectively. $\left(X_{r k}, Y_{r k}\right)$ are the input signals of each position-controlled loop filtered by applying the feedforward controllers $\left(Z_{1}, Z_{2}\right) \cdot\left(E_{x}, E_{y}\right)$ are axial errors for each axis and $\left(E_{z x}, E_{z y}\right)$ are the difference between the filtered input signals and the measured output signals. $\left(U_{x}, U_{y}\right)$ are the driving signals to each axis.

In general, the position controllers $\left(K_{p x}, K_{p y}\right)$ stabilize the control system while the feedforward controllers $\left(Z_{1}, Z_{2}\right)$ achieve improved performance for each axis. To analyze the tracking and contouring errors of the 2-DOF structured motion control system, the axial errors $\left(E_{x}, E_{y}\right)$ are derived as

$$
\begin{aligned}
& E_{x}=\frac{1}{1+P_{1} K_{p x}}\left[1+P_{1} K_{p x}\left(1-Z_{1}\right)\right] X_{r} \\
& E_{y}=\frac{1}{1+P_{2} K_{p y}}\left[1+P_{2} K_{p y}\left(1-Z_{2}\right)\right] Y_{r} .
\end{aligned}
$$

The tracking error, $e_{o}^{p}$, is thus

$$
e_{o}^{p}=\sqrt{E_{x}^{2}+E_{y}^{2}}
$$

\section{B. Contouring Error}

On the other hand, the contouring errors $\varepsilon_{o}^{p}$ can be further obtained from the geometrical relationship as [27]

$$
\varepsilon_{o}^{p}=E_{y} C_{y}-E_{x} C_{x}
$$

By substituting (1) into (2), the contouring error can be obtained as

$$
\begin{aligned}
\varepsilon_{o}^{p}= & \frac{1}{\left(1+P_{2} K_{p y}\right)\left(1+P_{1} K_{p x}\right)} \\
& \cdot\left[-C_{x}\left(1+P_{2} K_{p y}\right)\left[1+P_{1} K_{p x}\left(1-Z_{1}\right)\right]\right. \\
& \left.\quad C_{y}\left(1+P_{1} K_{p x}\right)\left[1+P_{2} K_{y}\left(1-Z_{2}\right)\right]\right]\left[\begin{array}{c}
X_{r} \\
Y_{r}
\end{array}\right]
\end{aligned}
$$

where $\left(C_{x}, C_{y}\right)$ are the cross-coupling gains changed according to the contour path [26], [27]. For linear contours, the gains $\left(C_{x}, C_{y}\right)$ are determined as

$$
\begin{aligned}
& C_{x}=\sin \theta \\
& C_{y}=\cos \theta
\end{aligned}
$$

where $\theta$ is the inclination angle of a linear contour with respect to the $X$-axis. For circular contours, the variable gains $\left(C_{x}, C_{y}\right)$ are determined as

$$
\begin{aligned}
& C_{x}=\sin \theta-\frac{E_{x}}{2 R} \\
& C_{y}=\cos \theta+\frac{E_{y}}{2 R}
\end{aligned}
$$

where $R$ is the circular contour radius, $\left(E_{x}, E_{y}\right)$ are the $X$ axis and $Y$-axis error signals respectively, and $\theta$ is the traversal angle of the circular contour. By defining

$$
M_{x}=Z_{1} \cdot \frac{K_{p x} P_{1}}{1+K_{p x} P_{1}}, \quad M_{y}=Z_{2} \cdot \frac{K_{p y} P_{2}}{1+K_{p y} P_{2}}
$$

the axial tracking error and the contouring error can be represented simply as

$$
\begin{aligned}
E_{x} & =\left(1-M_{x}\right) X_{r} ; \quad E_{y}=\left(1-M_{y}\right) Y_{r} \\
\varepsilon_{o}^{p} & =-C_{x}\left(1-M_{x}\right) X_{r}+C_{y}\left(1-M_{y}\right) Y_{r} .
\end{aligned}
$$

Note that $\left(M_{x}, M_{y}\right)$ are the transfer functions of the position feedback loop with feedforward controllers for the two axes.

Theoretically, by examining (9) and (10), tracking and contouring accuracy can be achieved by designing suitable position feedback loop controllers $\left(K_{p x}, K_{p y}\right)$ and feedforward controllers $\left(Z_{1}, Z_{2}\right)$. However, in practice, the improvement of tracking and contouring accuracy is limited because of the inherent servo lag, stick friction, and backlash in realmotion systems. To further improve the contouring accuracy of the two-axis motion control systems, the CCC was proposed by Koren and Lo [21], [27] and applied to the 2-DOF structured motion control systems by Houng and Hsu [30]. The integration of the feedforward controller and cross-coupled 
controller for the two-axis motion control system, as shown in Fig. 3, achieves significant error reduction in both tracking and contouring [30].

\section{Error of the Integrated System}

As shown in Fig. 3, $\left(C_{x}, C_{y}\right)$ are cross-coupling gains as described by (4)-(7) where $C$ is the CCC. In addition to the contouring error without the $\mathrm{CCC}$ as $\varepsilon_{o}^{p}, \varepsilon_{c}^{p}$, is the contouring error of the present integrated control system with CCC. The tracking and contouring errors as shown in Fig. 3 are derived. The axial errors $\left(E_{x}, E_{y}\right)$ of each axis are obtained as

$$
\begin{aligned}
& E_{x}=\frac{1}{1+P_{1} K_{p x}}\left\{\left[1+P_{1} K_{p x}\left(1-Z_{1}\right)\right] X_{r}+C \varepsilon_{c}^{p} C_{x} P_{1}\right\} \\
& E_{y}=\frac{1}{1+P_{2} K_{p y}}\left\{\left[1+P_{2} K_{p y}\left(1-Z_{2}\right)\right] Y_{r}-C \varepsilon_{c}^{p} C_{y} P_{2}\right\} .
\end{aligned}
$$

Moreover, the contouring errors $\varepsilon_{c}^{p}$ are obtained as

By substituting (8) and (13) into (11) and (12), the axial errors $\left(E_{x}, E_{y}\right)$ are

With proper feedforward controllers $\left(Z_{1}, Z_{2}\right)$ and a crosscoupled controller $C$, as in (13) and (14), shown at the bottom of the page, improving integrated control systems with both improved tracking and contouring accuracy is feasible [30].

\section{INTEGRATED CONTROLLER DESIGN}

The concerns of the controller design for the present integrated system are as follows.

1) Since the nonminimum phase system always exists in the sampling process [31]-[34], a suitable feedforward controller which gives a desirable bandwidth cannot be designed by simply canceling the poles and zeros.

2) The cross-coupling gains in CCC vary according to different contours [26], [27]. Thus, a sufficient stability margin of the parameter-varying integrated system is required when different contour commands are executed.

3) Since the integrated control system is in a multidegreeof-freedom and multiloop structure, its controller design procedures are relatively complicated.

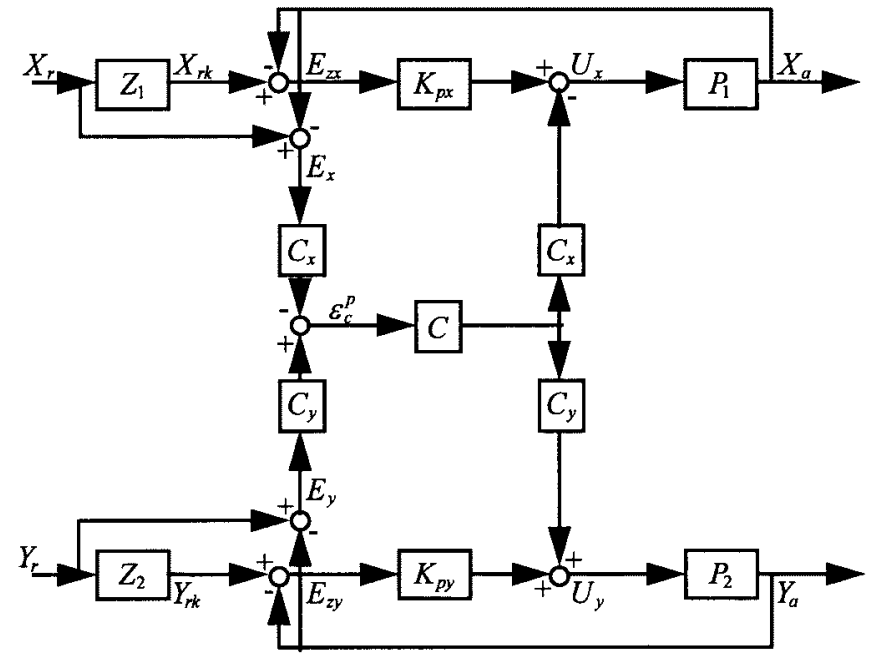

Fig. 3. The integrated control system.

\section{A. The Independent Design for Two Controllers}

Regarding (3) and (13), the important relationship for the contouring errors (subscript " $O$ " is without CCC; subscript " $c$ " is with $\mathrm{CCC}$ ) is obtained as

$$
\varepsilon_{c}^{p}=\frac{1}{1+C K} \varepsilon_{o}^{p}=H \cdot \varepsilon_{o}^{p}
$$

where

$$
K=\frac{\left(1+K_{p x} P_{1}\right) C_{y} C_{y} P_{2}+\left(1+K_{p y} P_{2}\right) C_{x} C_{x} P_{1}}{\left(1+K_{p x} P_{1}\right)\left(1+K_{p y} P_{2}\right)}
$$

$C$ designed CCC;

$H=1 /(1+C K)$ contouring error transfer function

$$
\text { (CETF) [29]. }
$$

According to (15), the design procedures of the integrated controller can be simplified as follows.

1) The CETF represents the contouring errors between systems with and without the coupling $C$.

2) The CETF is equivalent to the sensitivity function in an SISO control system, as shown in Fig. 4.

Since the tracking error which dominates $\varepsilon_{o}^{p}$ in (15) can be individually improved by applying feedforward controllers, the present integrated controller can achieve the improvement of contouring accuracy. Equation (15) indicates that the

$$
\begin{aligned}
& \varepsilon_{c}^{p}=\frac{1}{\left(1+P_{2} K_{p y}\right)\left(1+P_{1} K_{p x}\right)+\left(1+P_{1} K_{p x}\right) C C_{y} C_{y} P_{2}+\left(1+P_{2} K_{p y}\right) C C_{x} C_{x} P_{1}} \\
& \cdot\left[-C_{x}\left(1+P_{2} K_{p y}\right)\left[1+P_{1} K_{p x}\left(1-Z_{1}\right)\right] \quad C_{y}\left(1+P_{1} K_{p x}\right)\left[1+P_{2} K_{p y}\left(1-Z_{2}\right)\right]\right]\left[\begin{array}{c}
X_{r} \\
Y_{r}
\end{array}\right] \\
& {\left[\begin{array}{c}
E_{x} \\
E_{y}
\end{array}\right]=\left[\begin{array}{c}
X_{r} \\
Y_{r}
\end{array}\right]-\left[\begin{array}{c}
X_{a} \\
Y_{a}
\end{array}\right]=\frac{1}{\left(1+K_{p x} P_{1}\right)\left(1+K_{p y} P_{2}\right)+C C_{y} C_{y} P_{2}\left(1+K_{p x} P_{1}\right)+C C_{x} C_{x} P_{1}\left(1+K_{p y} P_{2}\right)}} \\
& \cdot\left[\begin{array}{cc}
\left(1-M_{x}\right)\left(1+K_{p x} P_{1}\right)\left(1+K_{p y} P_{2}+C C_{y} C_{y} P_{2}\right) & C C_{x} C_{y} P_{1}\left(1+K_{p y} P_{2}\right)\left(1-M_{y}\right) \\
C C_{x} C_{y} P_{2}\left(1+K_{p x} P_{1}\right)\left(1-M_{x}\right) & \left(1-M_{y}\right)\left(1+K_{p y} P_{2}\right)\left(1+K_{p x} P_{1}+C C_{x} C_{x} P_{1}\right)
\end{array}\right]\left[\begin{array}{c}
X_{r} \\
Y_{r}
\end{array}\right]
\end{aligned}
$$




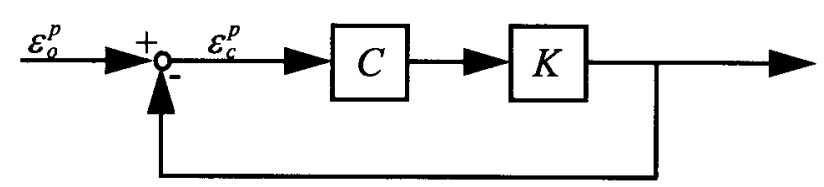

Fig. 4. The equivalent SISO control system.

minimization of the contouring error $\varepsilon_{c}^{p}$ can be found by designing a suitable frequency response of the CETF as in (15). Moreover, the contouring error $\varepsilon_{0}^{p}$ can be directly reduced by applying the feedforward controller design. Thus, the feedforward and the cross-coupled controller can be designed separately for the present integrated control systems.

\section{B. The Optimal Feedforward Controller Design}

Theoretically, to reduce axial errors $\left(E_{x}, E_{y}\right)$ and the contouring error $\varepsilon_{o}^{p}$, the feedforward controllers $\left(Z_{1}, Z_{2}\right)$ are designed so that the transfer functions $\left(M_{x}, M_{y}\right)$ can keep the frequency response with a unity gain and zero phase shift. The ZPETC can be directly obtained and is a practical feedforward controller in motion systems [10]. Basically, the design of the ZPETC controller directly cancels the stable poles and welldamped zeros in the position feedback loop and compensates for the unstable and lightly damped zeros to achieve both the zero phase error and a unity dc gain frequency response.

Suppose the feedforward controller is $Z_{p}\left(z^{-1}\right)$ and the position feedback loop transfer function $T\left(z^{-1}\right)$ is represented as

$$
\begin{aligned}
T\left(z^{-1}\right) & =\frac{K_{p x}\left(z^{-1}\right)}{1+K_{p x} P_{1}\left(z^{-1}\right)}=\frac{z^{-d} B\left(z^{-1}\right)}{A\left(z^{-1}\right)} \\
& =\frac{z^{-d} B_{a}\left(z^{-1}\right) B_{u}\left(z^{-1}\right)}{\hat{A}\left(z^{-1}\right)}
\end{aligned}
$$

where

$$
\begin{aligned}
A\left(z^{-1}\right)= & 1+a_{1} z^{-1}+a_{2} z^{-2}+\cdots+z_{n} z^{-n} \\
B\left(z^{-1}\right)= & b_{0}+b_{1} z^{-1}+b_{2} z^{-2}+\cdots+b_{m} z^{-m} \\
\hat{A}\left(z^{-1}\right)= & \hat{a}_{0}+\hat{a}_{1} z^{-1}+\hat{a}_{2} z^{-2}+\cdots+a_{n} z^{-n} \\
\hat{B}\left(z^{-1}\right)= & 1+\hat{b}_{1} z^{-1}+\hat{b}_{2} z^{-2}+\cdots+\hat{b}_{m} z^{-m} \\
B_{a}\left(z^{-1}\right)= & 1+b_{1}^{a} z^{-1}+b_{2}^{a} z^{-2}+\cdots+b_{q}^{a} z^{-q} \\
& \text { polynomials with acceptable zeros. } \\
B_{u}\left(z^{-1}\right)= & 1+b_{1}^{u} z^{-1}+b_{2}^{u} z^{-2}+\cdots+b_{p}^{u} z^{-p} \\
& \text { polynomials with unacceptable zeros. }
\end{aligned}
$$

the ZPETC is thus obtained as [10]

$$
Z_{p}\left(z^{-1}\right)=\left(\frac{B_{u}(z)}{B_{u}(1)^{2}}\right) \cdot\left(\frac{z^{d} \hat{A}\left(z^{-1}\right)}{B_{a}\left(z^{-1}\right)}\right) .
$$

The ZPETC is designed directly to achieve the zero-phase error. However, its frequency response in magnitude is satisfactory only in the low-frequency range. To increase the bandwidth of the ZPETC controlled system, the modified version of ZPETC [11]-[14] and the optimal ZPETC [15]-[20] are developed to further improve tracking accuracy.
An effective optimal ZPETC design method is summarized here [20]. Assume the optimal ZPETC $Z_{p}\left(z^{-1}\right)$ is designed with a digital prefilter (DPF) as

$$
Z_{p}\left(z^{-1}\right)=\operatorname{DPF}\left(z^{-1}\right) \cdot \frac{z^{d} \hat{A}\left(z^{-1}\right)}{B_{a}\left(z^{-1}\right)}
$$

where

$$
\begin{aligned}
\operatorname{DPF}\left(z^{-1}\right) & =\operatorname{DPF}_{M}\left(z^{-1}\right) \cdot \operatorname{DPF}_{P}\left(z^{-1}\right) \\
\operatorname{DPF}_{P}\left(z^{-1}\right) & =\frac{B_{u}(z)}{B_{u}(1)^{2}} \\
\operatorname{DPF}_{M}\left(z^{-1}\right) & =\sum_{k=0}^{N-P} \alpha_{k} \cdot\left(z^{k}+z^{-k}\right) .
\end{aligned}
$$

and

$N$ Order of DPF $\left(z^{-1}\right)$.

$P$ Number of unacceptable zeros in the position feedback loop.

Thus, the transfer function $R\left(z^{-1}\right)$ of the whole control system becomes

$$
R\left(z^{-1}\right)=Z_{p}\left(z^{-1}\right) \cdot T\left(z^{-1}\right)=\operatorname{DPF}\left(z^{-1}\right) \cdot B_{u}\left(z^{-1}\right) .
$$

Parameters $\alpha_{k}, k=0,1, \cdots$, and $N-P$ of the $\operatorname{DPF}_{M}\left(z^{-1}\right)$ can be solved through the Lagrange optimization method.

Define the Lagrange function $\Gamma(\alpha, \lambda)$ as

$\Gamma(\alpha, \lambda)=\frac{1}{2 \pi} \int_{w_{1}}^{w_{2}}\left|G_{e}\left(e^{-j w}\right)\right|^{2} d w+\lambda\left[\left.R\left(e^{-j w}\right)\right|_{w=0}-1\right]$

where

$\lambda$ is the Lagrange Multiplier and

$$
\begin{aligned}
G_{e}\left(e^{-j w}\right) & =R\left(e^{-j w}\right)-1 \\
R\left(e^{j w}\right) & =\left[\sum_{i=0}^{P} \gamma_{i}(2 \cos (i w))\right]\left[\sum_{k=0}^{N-P} \alpha_{k}(2 \cos (k w))\right] \\
& =\gamma^{T} A . \alpha
\end{aligned}
$$

The optimal parameter vector $\alpha$ of the digital prefilter $\operatorname{DPF}_{M}\left(z^{-1}\right)$ is obtained as

$$
\alpha=A_{1}^{-1}\left\{A_{2}^{T} \gamma+\frac{1-\beta^{T} A_{1}^{-1} A_{2}^{T} \gamma}{\beta^{T} A_{1}^{-1} \beta} \beta\right\}
$$

where

$$
\begin{aligned}
\alpha & \left.=\left[\begin{array}{llll}
\alpha_{0} & \alpha_{1} & \cdots & \alpha_{N-P}
\end{array}\right]_{[(N-P+1) \times 1}^{T}\right] \\
\beta & =\left[\begin{array}{llll}
2 & 2 & \cdots & \alpha_{N-P}
\end{array}\right]_{[(N-P+1) \times 1}^{T} \\
\gamma & =\left[\begin{array}{llll}
\gamma_{0} & \gamma_{1} & \cdots & \gamma_{p}
\end{array}\right]_{[(P+1) \times 1]}^{T} .
\end{aligned}
$$

and the matrix shown at the bottom of the following page.

$$
\begin{aligned}
& A_{1}=\frac{1}{2 \pi} \int_{w_{1}}^{w_{2}} A^{T} \gamma \gamma^{T} A d w \\
& A_{2}=\frac{1}{2 \pi} \int_{w_{1}}^{w_{2}} A d w .
\end{aligned}
$$


Thus, the optimal ZPETC is obtained as

$$
\begin{aligned}
Z_{p}\left(z^{-1}\right)= & \left(\sum_{k=0}^{N-P} \alpha_{k} \cdot\left(z^{k}+z^{-k}\right)\right) \\
& \cdot\left(\frac{B_{u}(z)}{B_{u}(1)^{2}}\right) \cdot\left(\frac{z^{d} \hat{A}\left(z^{-1}\right)}{B_{a}\left(z^{-1}\right)}\right) .
\end{aligned}
$$

To reduce the influence of parameter variation and external load perturbation, the adaptive ZPETC [20], [35] can also be used to compensate for the unknown inputs with simple estimation techniques. Likewise, other feedforward controller design algorithms [36]-[41] can also be directly applied to obtain certain characteristics in the proposed integrated control systems.

\section{The Robust Cross-Coupled Controller Design}

In the past, CCC was generally achieved in a PID form with suitable tuning. The CCC design problem was not solved until the CETF was developed by Yeh and Hsu [29]. Note that in (15), the CETF is similar to the sensitivity function in a feedback control system. Consequently, the design goals of compensator $\mathrm{C}$ in CCC become 1) reducing the contouring error $\varepsilon_{c}^{p}$ and 2) stabilizing the equivalent system as shown in Fig. 4. Thus, with the present CETF formulation, various robust algorithms for controller design can be directly employed to achieve desirable stability margins and performance. Moreover, the compensator $C$ design in the present CCC for the two-axis servo system can be simplified to a single-loop design problem.

Here, the authors adopted the quantitative feedback theory (QFT) design algorithm [42] to achieve a robust CCC design with a desirable stability margin. The QFT algorithm moves the template of the rational function $K$ to meet design specifications by a robust compensator $C$ at certain reference frequencies. Thus, the present integrated controller can be applied to different contouring commands under varying crosscoupling gains. The template can be constructed by varying the cross-coupling gains from -1 to one according to (4)-(7). The gain and the phase responses of the rational function $C K$ can be represented as

$$
\begin{aligned}
\left|C K\left(e^{-j \omega_{o}}\right)\right|_{\mathrm{dB}}= & \left|C\left(e^{-j \omega_{o}}\right)\right|_{\mathrm{dB}}+\left|K\left(e^{-j \omega_{o}}\right)\right|_{\mathrm{dB}} \\
\angle\left[C K\left(e^{-j \omega_{o}}\right)\right]_{\text {degree }}= & \angle\left[C\left(e^{-j \omega_{o}}\right)\right]_{\text {degree }} \\
& +\angle\left[K\left(e^{-j \omega_{o}}\right)\right]_{\text {degree }}
\end{aligned}
$$

The frequency response of is shifted by $K\left(e^{-j \omega_{0}}\right)$ is shifted by $\left(\angle\left[C\left(e^{-j \omega_{o}}\right)\right]_{\text {degree }},\left|C\left(e^{-j \omega_{o}}\right)\right|_{\mathrm{dB}}\right)$ according to the compensator frequency response $C\left(e^{-j \omega_{0}}\right)$ at the reference frequency $\omega=\omega_{0}(\mathrm{rad} / \mathrm{s})$, and the template of the rational function $K$ is thus shifted according to the design of the robust compensator $C$. Therefore, the present robust compensator $C$ can be designed so that the frequency responses of the rational function $C K$ at certain reference frequencies can meet the design specifications.

By considering the gain response of the CETF, the QFT design algorithm can be represented on the inverse Nichol's chart. Each point on the same curve on the inverse Nichol's chart implies the same magnitude $M$ of the transfer function $H$; i.e., $M=|H|=|1 /(1+C K)|$, and each point on the inverse Nichol's chart is the magnitude and phase frequency response of the rational function $C K$. Thus, the template of the rational function $K$ has to be moved into a suitable region by applying lead or lag compensators to keep the frequency response of the rational function $C K$ with the specified gain margin, phase margin, and suitable gain response of the CETF. Thus, the proposed robust CCC design maintains system stability and reduces contouring error even when the crosscoupling gains vary along the contour path or under different contour commands.

\section{Stability Analysis for the Integrated Control System}

Theorem 1: In internally connected systems, the input signals, denoted as $v_{i}$, are injected into each internal connection point to result in the mixed output signals, denoted as $w_{j}$. The internally connected systems are internally stable if the set of input signals $v_{i}$ and output signals $w_{j}$ are bounded-inputbounded-output (BIBO) stable.

Proof: See [43].

Theorem 2: If the integrated controlled system is designed to meet the following requirements.

(A1) with feedforward controllers, the position feedback loop controller $\left(K_{p x}, K_{p y}\right)$ achieves internal stability for each axis, and

(A2) the equivalent SISO control system, as shown in Fig. 4, remains internally stable as the cross-coupling gains $\left(C_{x}, C_{y}\right)$ are varied, then the designed integrated control system as shown in Fig. 3 is internally stable.

Proof: The authors can prove this theorem by examining the transfer function between the injected input $v_{i}$ and the mixed output $w_{j}$. Define two rational functions, $\alpha$ and $\beta$, as

$$
\begin{aligned}
\alpha & =\left(1+K_{p x} P_{1}\right)\left(1+K_{p y} P_{2}\right) \\
\beta & =\left(1+K_{p x} P_{1}\right) C C_{y} C_{y} P_{2}+\left(1+K_{p y} P_{2}\right) C C_{x} C_{x} P_{1} .
\end{aligned}
$$

Clearly, requirements (A1) and (A2) achieve all stable zeros of the rational function $(\alpha+\beta)$. Since the poles of the rational function $(\alpha+\beta)$ contain the poles of the forward path gains between each injected bounded input $v_{i}$ and each mixed output

$$
A=4 \cdot\left[\begin{array}{cccc}
1 & \cos (w) & \cdots & \cos ((n-P) w) \\
\cos (w) & \frac{1}{2}[\cos (2 w)+1] & \cdots & \frac{1}{2}[\cos ((N-P+1) w)+\cos ((N-P-1) w)] \\
\vdots & \vdots & \ddots & \vdots \\
\cos (P w) & \frac{1}{2}[\cos ((P+1) w)+\cos ((P-1) w)] & \cdots & \frac{1}{2}[\cos (N w)+\cos ((N-2 P) w)]
\end{array}\right]
$$




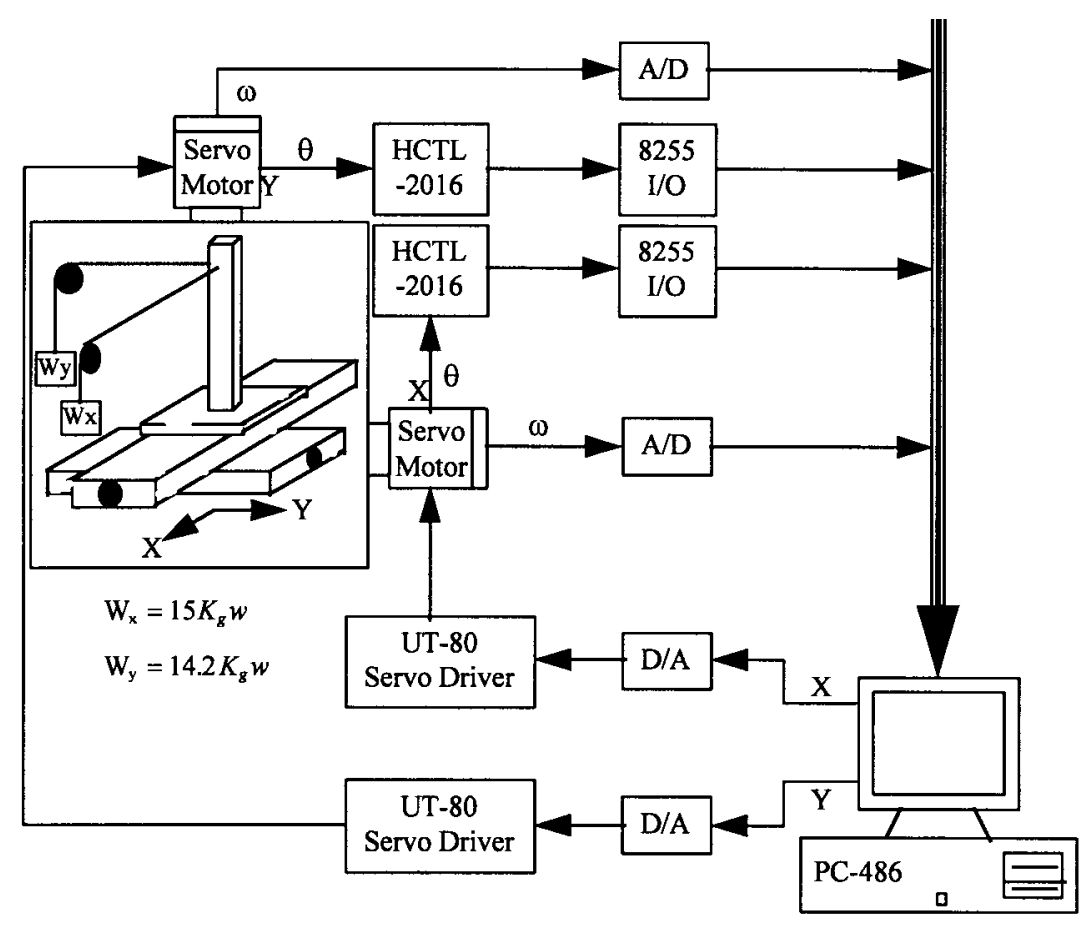

Fig. 5. The experimental setup.

TABLE I

The Specifications of the Servo System

\begin{tabular}{|c|c|c|}
\hline Components & Symbols & Units \\
\hline \multirow{4}{*}{ DC servo motor } & $L$ & $4.7 \mathrm{mH}$ \\
\cline { 2 - 3 } & $R$ & $3.1 \Omega$ \\
\cline { 2 - 3 } & $K_{t}$ & $0.21952 \mathrm{~N} \cdot \mathrm{m} / \mathrm{A}$ \\
\cline { 2 - 3 } & $J$ & $2.1756 \times 10^{-4} \mathrm{Kg} \cdot \mathrm{m}^{2}$ \\
\cline { 2 - 3 } & $B$ & $5.333 \times 10^{-4} \mathrm{~N} \cdot \mathrm{m} / \mathrm{rad} \cdot \mathrm{s}^{-1}$ \\
\cline { 2 - 3 } & $K_{b}$ & $0.21952 \mathrm{~N} / \mathrm{rad} \cdot \mathrm{s}^{-1}$ \\
\hline \multirow{2}{*}{ Current feedback gain } & $K_{a}$ & $0.2 \mathrm{~V} / \mathrm{A}$ \\
\hline Encoder gain & $K_{e}$ & $632.62 \mathrm{pulse} / \mathrm{rad}$ \\
\hline D/A gain & $K_{d}$ & $2.442 \times 10^{-3} \mathrm{~V} / \mathrm{pulse}$ \\
\hline Pitch of lead screw & $K_{l}$ & $5 \mathrm{~mm} / \mathrm{rev}$ \\
\hline
\end{tabular}

$w_{j}$, the poles of the transfer function for each injected bounded input $v_{i}$ and each mixed output $w_{j}$ of Fig. 3 are thus stable. Therefore, from Theorem 1, the integrated control system is internally stable.

According to the above discussion, the integrated control system which integrates the CCC and the feedforward controller reduces both contouring and tracking errors. Moreover, analysis and derivation of the integrated controller indicate that the design of the feedforward controller and the design of the coupled controller design can be mutually independent.
Furthermore, since $\varepsilon_{o}^{p}$ represents the contouring errors of an integrated control system without $\mathrm{CCC}$ and can be mainly reduced by applying the feedforward controllers, (15) shows that the contouring errors can be further improved by using the CCC. In summary, the integrated controller can thus be obtained as in the following procedures.

\section{Design Procedures}

Step 1: The tracking error in motion control is reduced by implementing a feedforward controller. 
TABLE II

EXPERIMENTAL RESUlTS FOR CORNER CONTOUR

\begin{tabular}{|c|c|c|c|c|}
\hline Measurement & \multicolumn{2}{|c|}{ Contouring error } & \multicolumn{2}{c|}{ Tracking error } \\
\hline $\begin{array}{c}\text { Performance } \\
\text { Index } \\
\text { Controller }\end{array}$ & $\begin{array}{c}\text { IAE } \\
(\mathrm{mm})\end{array}$ & $\begin{array}{c}\text { ISE } \\
\left(\mathrm{mm}^{2}\right)\end{array}$ & $\begin{array}{c}\text { IAE } \\
(\mathrm{mm})\end{array}$ & $\begin{array}{c}\text { ISE } \\
\left(\mathrm{mm}^{2}\right)\end{array}$ \\
\hline $\mathrm{P}$ & 84.2830 & 20.9796 & 1877.1288 & 1874.1450 \\
\hline optimal ZPETC & 65.7925 & 3.1877 & 137.5563 & 11.6415 \\
\hline robust CCC & 38.2333 & 11.0211 & 1850.1986 & 1823.0182 \\
\hline $\begin{array}{c}\text { robust CCC+ } \\
\text { optimal ZPETC }\end{array}$ & 20.9406 & 0.4128 & 102.1267 & 8.4517 \\
\hline
\end{tabular}

TABLE III

EXPERIMENTAL Results FOR Circular Contour

\begin{tabular}{|c|c|c|c|c|}
\hline $\begin{array}{c}\text { Measurement } \\
\text { Controller }\end{array}$ & \multicolumn{2}{|c|}{ Contouring errors } & \multicolumn{2}{c|}{ Tracking errors } \\
\hline $\mathrm{P}$ & $\begin{array}{c}\text { IAE } \\
(\mathrm{mm})\end{array}$ & $\begin{array}{c}\text { ISE } \\
\left(\mathrm{mm}^{2}\right)\end{array}$ & $\begin{array}{c}\text { IAE } \\
(\mathrm{mm})\end{array}$ & $\begin{array}{c}\text { ISE } \\
\left(\mathrm{mm}^{2}\right)\end{array}$ \\
\hline optimal ZPETC & 26.9436 & 1.3908 & 452.1091 & 190.1873 \\
\hline robust CCC & 15.7742 & 0.9972 & 48.8576 & 2.6137 \\
\hline $\begin{array}{c}\text { robust CCC+ } \\
\text { optimal ZPETC }\end{array}$ & 13.0707 & 0.2549 & 455.0466 & 192.7584 \\
\hline
\end{tabular}

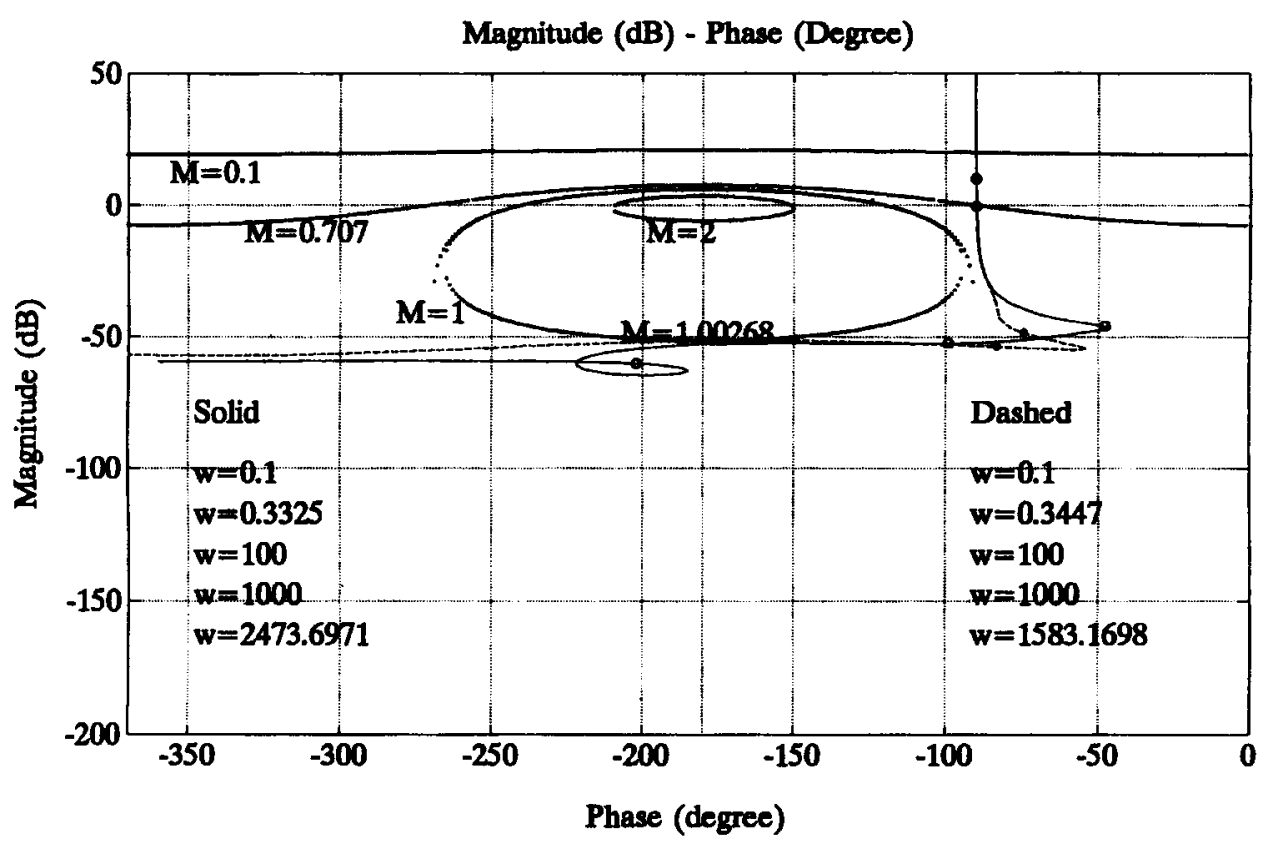

Fig. 6. The gain-phase plot of the rational function $C K$. (Solid: $\theta=79.38^{\circ}, C_{x}=0.9829, C_{y}=0.1843$.) (Dashed: $\theta=13.24^{\circ}$, $\left.C_{x}=0.2290, C_{y}=0.9734.\right)$

Step 2: CCC is next implemented to further reduce the contouring error of the system.

Thus, both the tracking accuracy and contouring accuracy for the present integrated control system are obtained. If frequency responses and stability are specified, both the optimal ZPETC and the robust CCC can be directly adopted in the present integrated system.

\section{EXPERIMENTAL RESULTS}

The experimental setup for the present study is shown in Fig. 5. A PC-486 generated control commands and recorded signals including the input commands for different contours, the implementation of a robust variable-gain CCC controller, the optimal ZPETC controller, and the control inputs to the 


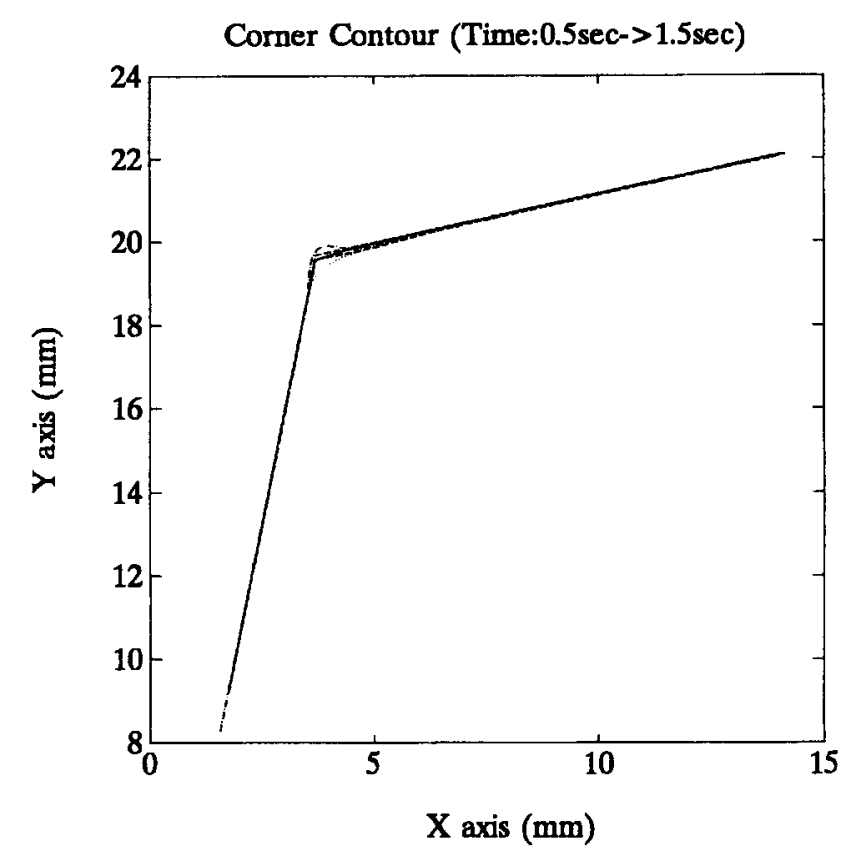

(a)

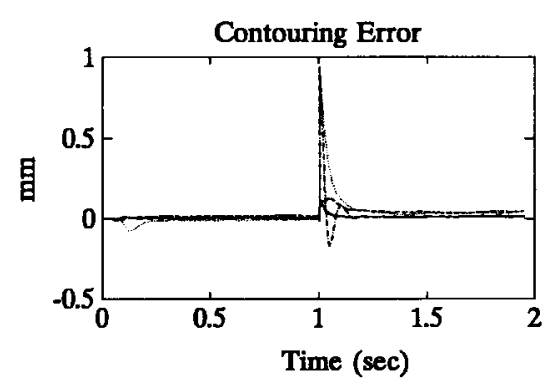

(b)

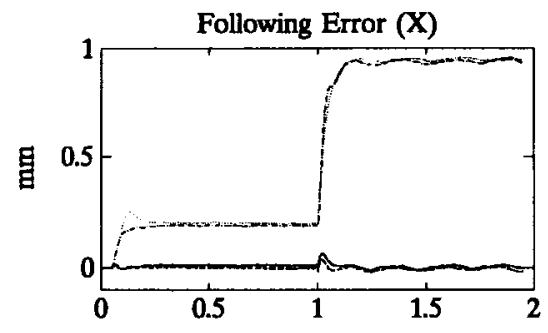

(d)

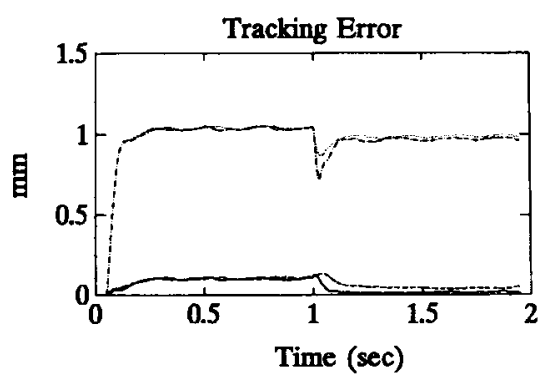

(c)

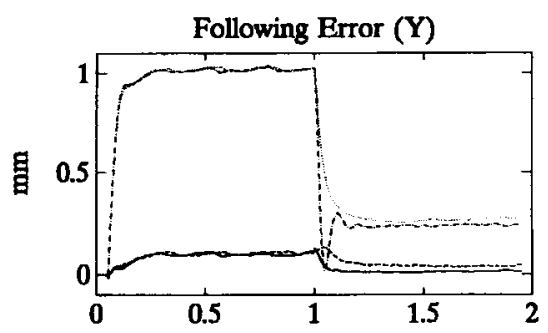

(e)

Fig. 7. Experimental results for corner contour. $\cdots \cdots \cdots \cdots \mathrm{P} ;-\cdot-\cdot-\cdots$ robust CCC; -- - - - optimal ZPETC; $\longrightarrow$ robust CCC; + optimal ZPETC.

velocity loop. A Sanyo UT-80 DC servo driver included an analog current feedback signal, a velocity loop, a current loop, and a PWM output. The computer sent and received the control inputs and position outputs through the interface of an $\mathrm{AD} / \mathrm{DA}$ card at a sampling period of $1 \mathrm{~ms}$. The specifications of the present servo system is provided in Table I.
Step 1: The controlled plants $\left(P_{1}, P_{2}\right)$ of the two axes were identified as

$$
\begin{aligned}
0.0026 z^{-1}+0.005 z^{-2}+0.0018 z^{-3} \\
P_{1}\left(z^{-1}\right)=\frac{+0.0022 z^{-4}-0.0003 z^{-5}+0.0006 z^{-6}}{1-} \\
+0.5957 z^{-1}+0.5804 z^{-2}-0.322 z^{-3} \\
+0.3099 z^{-4}+0.1701 z^{-5}-0.2070 z^{-6} \\
+0.11 z^{-7}-0.0456 z^{-8}
\end{aligned}
$$




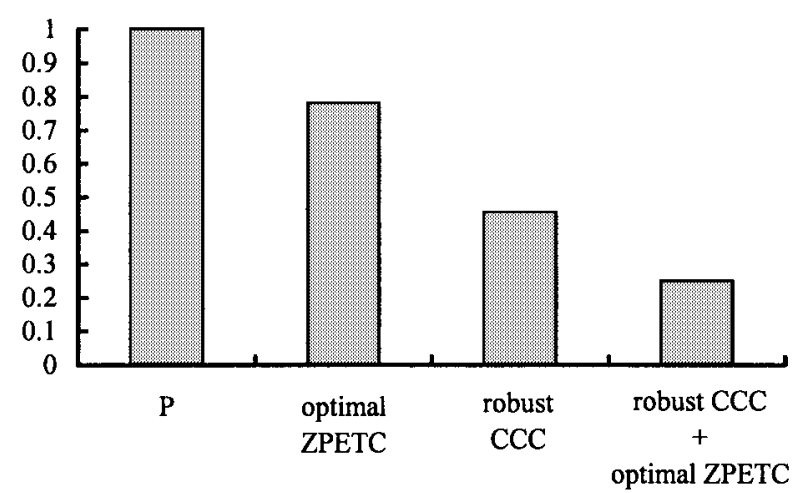

(a)

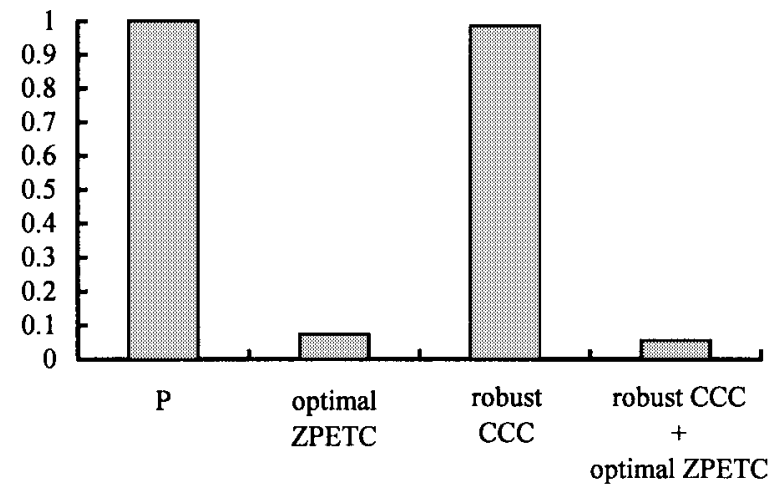

(b)

Fig. 8. Performance index comparison for corner contour. (a) IAE for contouring errors, (b) IAE for tracking errors.

$$
\begin{aligned}
& 0.0023 z^{-1}+0.0031 z^{-2}+0.0015 z^{-3} \\
& P_{2}\left(z^{-1}\right)=\frac{-0.0003 z^{-4}-0.0036 z^{-5}+0.0003 z^{-6}}{1-1.5578 z^{-1}+0.3473 z^{-2}-0.1946 z^{-3}} \\
& +0.3141 z^{-4}+0.1933 z^{-5}-0.102 z^{-6} \\
& +0.1997 z^{-7}-0.2001 z^{-8} \text {. }
\end{aligned}
$$

Step 2: The proportional controllers $\left(K_{p x}, K_{p y}\right)$ used for the position loop were 0.2800 and 0.2544 , respectively. Thus, the control system was stabilized with matched gains for the two axes [44].

Step 3: By choosing a fourth- and sixth-order DPF for the $X$ and $Y$ axes, respectively, the optimal ZPETC for the two axes were obtained as [20]

$$
\begin{aligned}
&- 4.795 z^{5}+49.717 z^{4}-252.268 z^{3} \\
&+848.922 z^{2}-823.067 z^{1}+77.951 \\
&-5.127 z^{-1}+3.897 z^{-2}+216.223 z^{-3} \\
&-136.223 z^{-4}+31.783 z^{-5}+8.576 z^{-6} \\
&-18.745 z^{-7}+5.836 z^{-8}-11.86 z^{-9} \\
& Z_{1}\left(z^{-1}\right)=+0.12 z^{-10} \\
& \hline 1+0.0917 z^{-1}+0.5216 z^{-2} \\
&-0.1308 z^{-3}+0.1313 z^{-4} \\
&- 33.05 z^{7}+236.92 z^{6}-710.70 z^{5} \\
&+1084.75 z^{4}-779.65 z^{3}+423.98 z^{2} \\
&-379.3 z^{1}-94.87+414.8 z^{-1} \\
&-302.24 z^{-2}+272.95 z^{-3}-149.77 z^{-4} \\
&+33.10 z^{-5}-2.77 z^{-6}-41.49 z^{-7} \\
&+43.62 z^{-8}-19.47 z^{-9}+3.41 z^{-10} \\
& Z_{2}\left(z^{-1}\right)= 1-0.8748 z^{-1}+0.0633 z^{-2 .}
\end{aligned}
$$

Step 4: By applying the QFT procedures, the robust CCC [29] with a gain margin of $50 \mathrm{~dB}$ and a phase margin of $90^{\circ}$ was designed as

$$
C\left(z^{-1}\right)=\frac{0.5-1.4625 z^{-1}+1.4713 z^{-2}-0.5504 z^{-3}}{+0.0417 z^{-4}} .
$$

The gain-phase plot of the rational function $C K$ for different cross-coupling gains $\left(C_{x}, C_{y}\right)$ is shown in Fig. 6.

Step 5: By combining the position loop gains in Step 2 with the optimal ZPETC and robust CCC obtained in Steps 3-4, respectively, the integrated control system is thus constructed.

Experiments were conducted under two typical motion commands.

1) The corner command included two linear commands. The first linear segment was with a $79.38^{\circ}$ inclination angle and a $20.3485-\mathrm{mm}$ length at a speed of 1.285 $\mathrm{m} / \mathrm{min}$. The second linear command was with a $13.24^{\circ}$ inclination angle and a $21.8303-\mathrm{mm}$ length at a speed of $1.3098 \mathrm{~m} / \mathrm{min}$.

2) The circular command was performed with a $1.5-\mathrm{mm}$ radius at a speed of $0.4712 \mathrm{~m} / \mathrm{min}$.

The experimental results for the corner command are shown in Fig. 7 and summarized in Table II. Fig. 8 is the bar chart for the indexes IAE and ISE, the integration of the absolute error and squared error, respectively, normalized with the results of the $\mathrm{P}$ controller. The experimental results for the circular command are also shown in Fig. 9 and are summarized in Table III. Fig. 10 is the bar chart of IAE and ISE also normalized with the results of the $\mathrm{P}$ controller.

According to the experimental results, the proposed integrated control system renders the best performance in both the tracking and contouring accuracy. A discussion of the integrated controller follows.

1) Although tracking accuracy is greatly improved by implementing a ZPETC, reduction of the contouring errors is limited because of modeling error and nonlinearity in real mechanical systems.

2) When the CCC is further appended to the ZPETC to form the integrated control system, both tracking error and contouring error significantly decrease.

3 ) As the motion command changes suddenly, for example, at the corner, its contouring error increases significantly. In a general $\mathrm{CCC}$, such increasing contouring error can be reduced by including a time-delay command at the corner in practice. In the present integrated system, the contouring error due to a sudden changing command is effectively suppressed because the included feedforward controller greatly reduces the corresponding tracking error.

In fact, different types of feedforward controllers and CCC's can be employed in the proposed integrated controller. In this paper, the present control system integrates the optimal ZPETC [20] and the robust CCC [29] to provide sufficient frequency responses and gain-phase margin with systematic 


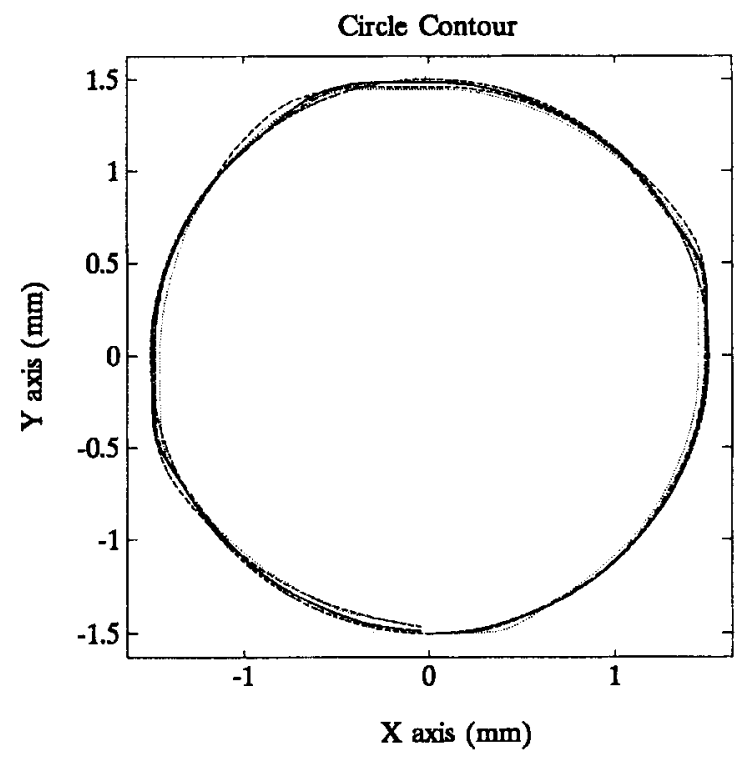

(a)

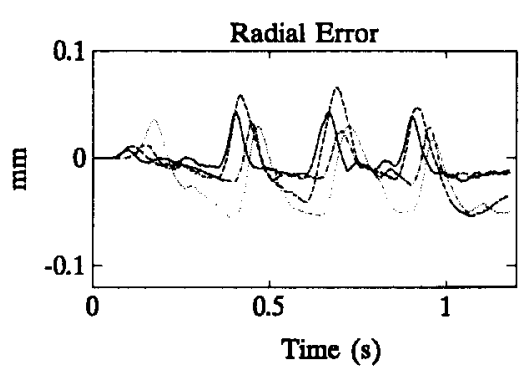

(b)

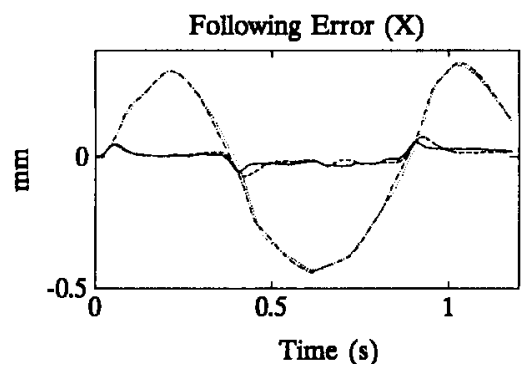

(d)

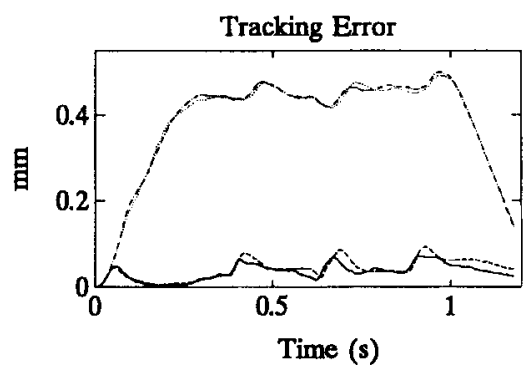

(c)

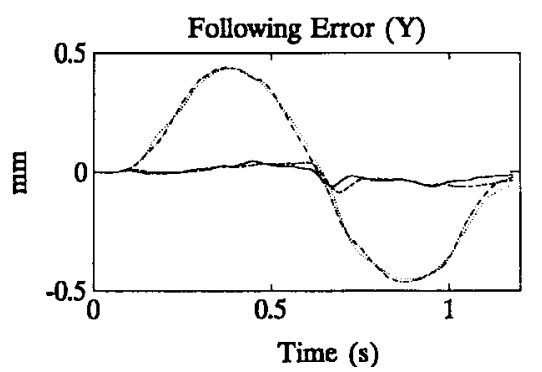

(e)

Fig. 9. Experimental results for circular contour. $\ldots \ldots \ldots \ldots \mathrm{P} ;-$. $_{-}$ robust CCC; + optimal ZPETC.

design procedures. Therefore, the present system can be applied more widely to different commands in real applications. Experimental results also indicate that both contouring error and tracking error of this integrated controller under different contouring commands are greatly reduced. Note that the present PC-486 is capable of handling all control computations with the eighth-order identified plants, the fourth- and sixthorder DPF for optimal ZPETC, and the fourth-order CCC. Lower order models can be chosen for those design with a tradeoff between control performance and implementation cost. In real applications, the design based on a fourth-order plant model renders satisfactory results [20].

\section{CONCLUSIONS}

In motion control systems, tracking errors can be reduced by applying suitable feedforward control design. Moreover, the present CETF analysis in (15) indicates that contouring error can be reduced by applying CCC. The proposed integrated controller which combines the ZPETC and the CCC leads to both tracking and contouring motion precision. Both the optimal ZPETC design, applying the Lagrange optimization method, and a robust CCC design, applying the QFT method, were employed in this study for the proposed integrated controller. The present optimal ZPETC with a digital prefilter 


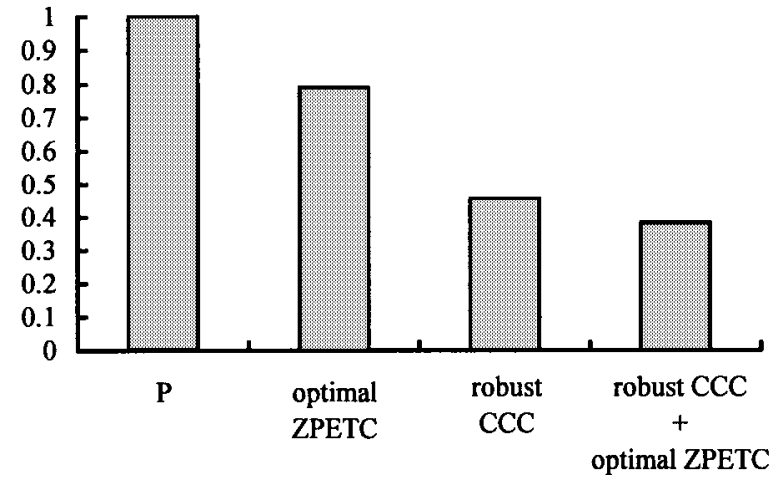

(a)

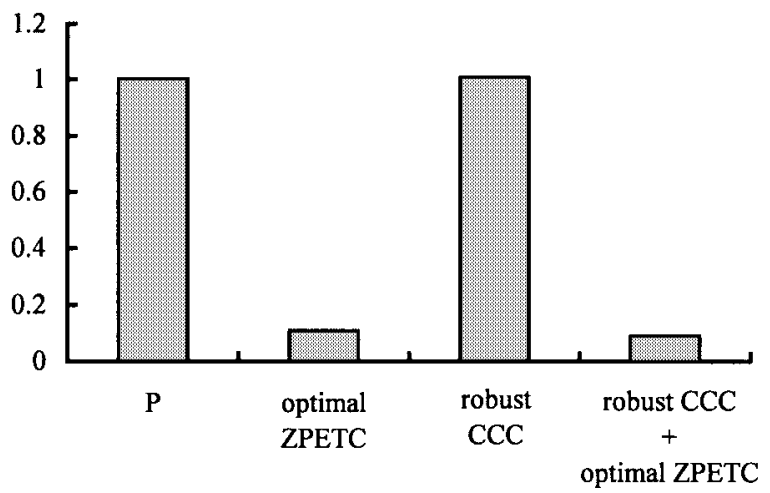

(b)

Fig. 10. Performance index comparison for circular contour. (a) IAE for contouring errors. (b) IAE for tracking errors.

is in a concise format and leads to more efficient computations compared to existing optimal ZPETC methods [15]-[20]. Furthermore, the present robust CCC renders desirable gain and phase margins while stability is not guaranteed in existing CCC methods [21]-[28]. Thus, the proposed integrated controller renders both tracking and contouring accuracy with desirable frequency responses and stability.

Theoretically, tracking error in motion control can be kept small enough to simultaneously reduce contouring error. Unfortunately, the improvement of tracking accuracy is limited because of 1) the unstable zeros in the plant of the feedforward control design; 2) system uncertainty and modeling errors; and 3) some unavoidable undesirable mechanical factors. Thus, accuracy in a real motion control system is limited if only an advanced feedforward controller is applied. Therefore, the role of the CCC in improving the contouring accuracy becomes more crucial. The proposed integrated controller includes both the feedforward and the cross-coupled controllers and it significantly reduces both the contouring and tracking errors.

System analysis of the proposed integrated controller concludes that the feedforward controller and the cross-coupled controller can be designed separately. Thus, systematic design procedures for the present integrated control system, which integrates the robust CCC and the optimal ZPETC, provide the desirable stability margin and bandwidth. Experimental results on a dc servo table also indicate that the present integrated controller gives satisfactory control performance and precision under different contouring commands.

\section{REFERENCES}

[1] Y. Koren, Computer Control of Manufacturing Systems. New York: McGraw-Hill, 1983.

[2] B. Armstrong-Helouvry, P. Dupont, and C. C. De Wit, "A survey of models, analysis tools and compensation methods for the control of machines with friction," Automatica, vol. 30, no. 7, pp. 1083-1138, 1994.

[3] B. Armstrong-Helouvry, "Stick slip and control in low-speed motion," IEEE Trans. Automat. Contr., vol. 38, pp. 1483-1496, 1993.

[4] C. Canudas, K. Astrom, and K. Braun, "Adaptive friction compensation in DC motor drives," IEEE J. Robot. Automat., vol. RA-3, pp. 681-685, 1987.

[5] P. E. Dupont, "Avoiding stick-slip through PD control," IEEE Trans. Automat. Contr., vol. 39, pp. 1094-1097, 1994.

[6] S. Jee and Y. Koren, "A self-organizing fuzzy logic control for friction compensation in feed drives," in Proc. 1995 Amer. Contr. Conf., 1995, pp. 205-209.

[7] H. S. Lee and M. Tomizuka, "Robust motion controller design for highaccuracy positioning systems," IEEE Trans. Ind. Electron., vol. 43, pp. 48-55, 1996.

[8] E. D. Tung, Y. Urushisaki, and M. Tomizuka, "Low-velocity friction compensation for machine tool feed drive," in Proc. 1993 Amer. Contr. Conf., 1993, pp. 1932-1936.

[9] S. Yang and M. Tomizuka, "Adaptive pulse width control for precise positioning under the influence of stiction and coulomb friction," $A S M E$ J. Dynamic Syst., Measurement, Contr., vol. 110, pp. 221-227, 1988.

[10] M. Tomizuka, "Zero phase error tracking algorithm for digital control," ASME J. Dynamic Syst., Measurement, Contr., vol. 109, pp. 65-68, 1987.

[11] B. Haack and M. Tomizuka, "The effect of adding zeros to feedforward controllers," ASME J. Dynamic Syst., Measurement, Contr., vol. 113 pp. 6-10, 1991

[12] D. Torfs, J. De Schutter, and J. Swevers, "Extended bandwidth zero phase error tracking control of nonminimum phase systems," ASME J. Dynamic Syst., Measurement Contr., vol. 114, pp. 347-351, 1992.

[13] M. Tomizuka, "On the design of digital tracking controllers," ASME J. Dyna. Syst., Measurement, Contr., vol. 115, no. 2(B), pp. 412-418, 1993.

[14] M. Weck and G. Ye, "Sharp corner tracking using the IKF control strategy," Ann. CIRP, vol. 39, pp. 437-441, 1990.

[15] Y. Funahashi and M. Yamada, "Zero phase error tracking controllers with optimal gain characteristics," ASME J. Dynamic Syst., Measurement, Contr., vol. 115, pp. 311-318, 1993.

[16] C. H. Menq and J. J. Chen, "Precision tracking control of discrete time nonminimum phase systems," ASME J. Dynamic Syst., Measurement, Contr., vol. 115, pp. 238-245, 1993.

[17] D. Torfs and J. De Schutter, "Optimal feedforward prefilter with frequency domain specification for nonminimum phase systems," ASME J. Dynamic Syst., Measurement, Contr., vol. 118, pp. 791-795, 1996.

[18] J. Z. Xia and C. H. Menq, "Precision tracking control of nonminimum phase systems with zero phase error," Int. J. Contr., vol. 61, no. 4, pp. 791-807, 1995.

[19] M. Yamada, Y. Funahashi, and S. Fujiwara, "Zero phase error tracking system with arbitrarily specified gain characteristics," ASME J. Dynamic Syst., Measurement, Contr., vol. 119, pp. 260-264, 1997.

[20] S. S. Yeh and P. L. Hsu, The Controller Design Strategies in Improving Contouring Accuracy for CNC Machines, Master thesis, Inst. Contr. Eng., NCTU, 1996.

[21] Y. Koren, "Cross-coupled biaxial computer for manufacturing systems," ASME J. Dynamic Syst., Measurement, Contr., vol. 102, no. 4, pp. 265-272, 1980.

[22] H. Y. Chuang and C. H. Liu, "A model reference adaptive control strategy for improving contour accuracy of multiaxis machine tools," IEEE Trans. Ind. Applicat., vol. 28, pp. 221-227, 1992.

[23] _ "Cross-coupled adaptive feedrate control for multiaxis machine tools," ASME J. Dynamic Syst., Measurement, Contr., vol. 113, no. 3, pp. 451-457, 1991

[24] L. Feng, Y. Koren, and J. Borenstein, "A model-reference adaptive motion controller for a differential-drive mobile robot," in Proc. 1994 Conf. Robot. Automat., vol. 4, pp. 3091-3096, 1994.

[25] Y. Koren and S. Jee, "Fuzzy logic cross-coupling control," CIRP Proc. Manufacturing Syst., vol. 25, no. 1, pp. 104-108, 1995.

[26] Y. Koren and C. C. Lo, "Advanced controller for feed drivers," Ann. CIRP, vol. 41, pp. 689-698, 1992.

[27] _ "Variable gain cross coupling controller for Contouring," Ann. CIRP, vol. 40, pp. 371-374, 1991.

[28] P. K. Kulkarni and K. Srinivasan, "Cross-coupled control of biaxial feed drive servo mechanisms," ASME J. Dynamic Syst., Measurement, Contr., vol. 112, no. 2, pp. 225-232, 1990. 
[29] S. S. Yeh and P. L. Hsu, "Theory and applications of the robust crosscoupled control design," in Proc. 1997 Amer. Contr. Conf., 1997, pp. 791-795.

[30] P. L. Hsu and Y. C. Houng, "An integrated controller design for precise CNC motion control," CIRP Proc. Manufacturing Syst., vol. 25, no. 1, pp. 109-118, 1995.

[31] K. J. Astrom, P. Hagander, and J. Sternby, "Zeros of sampled systems," Automatica, vol. 20, pp. 31-38, 1984.

[32] D. W. Clarke, "Self tuning control of nonminimum phase systems," Automatica, vol. 20, pp. 501-517, 1984.

[33] J. Golten and A. Verwer, Control System Design and Simulation. New York: McGraw-Hill, 1991.

[34] K. Ogata, Modern Control Engineering. Englewood Cliffs, NJ: Prentice-Hall, 1970.

[35] T. C. Tsao and M. Tomizuka, "Robust adaptive and repetitive digital tracking control and application to a hydraulic servo for noncircular machining," ASME J. Dynamic Syst., Measurement, Contr., vol. 116, pp. 24-32, 1994.

[36] R. A. Burdisso and C. R. Fuller, "Feedforward controller design by eigenvalue assignment," J. Guid. Contr. Dynamics, vol. 17, no. 3, pp. 466-472, 1994.

[37] E. Gross and M. Tomizuka, "Experimental flexible beam tip tracking control with a truncated series approximation to uncancelable inverse dynamics," IEEE Trans. Contr. Syst. Technol., vol. 2, 1994.

[38] S. Jayasuriya and M. Tomizuka, "Generalized feedforward controllers, perfect tracking and zero phase error," in Japan/USA Symp. Flexi. Autom., vol. 1, 1992, pp. 511-514.

[39] R. J. McNab and T. C. Tsao, "Frequency response based feedforward control design with uncertainty considerations," in Proc. 1997 Amer. Contr. Conf., 1997, pp. 2726-2730.

[40] T. C. Tsao, "Optimal feed-forward digital tracking controller design," ASME J. Dynamic Syst., Measurement, Contr., vol. 116, pp. 583-592, 1994.

[41] Y. Zhao and S. Jayasuriya, "Feedforward controllers and tracking accuracy in the presence of plant uncertainties," ASME J. Dynamic Syst. Measurement, Contr., vol. 117, pp. 490-495, 1995.

[42] I. M. Horowitz and M. Sidi, "Synthesis of feedback systems with large plant ignorance for prescribed time-domain tolerance," Int. J. Contr., vol. 16, no. 2, pp. 287-309, 1972.
[43] F. B. Yeh, Post Modern Control Theory and Design. Taipei, Taiwan: Eurasia, 1990

[44] A. Poo, J. G. Bollinger, and W. Younkin, "Dynamic error in type contouring systems," IEEE Trans. Ind. Applicat., vol. IA-8, pp. 477-484, 1972.

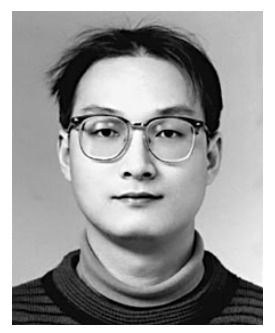

Syh-Shiuh Yeh received the B.S. degree in mechanical engineering and the M.S. degree in electrical and control engineering from National Chiao Tung University, Taiwan, R.O.C., in 1994 and 1996, respectively. He is currently a Ph.D. candidate in the Institute of Electrical and Control Engineering at National Chiao Tung University, Taiwan.

His research interests include motion system and control design.

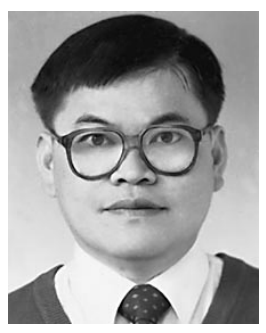

Pau-Lo Hsu (M'92) was born into a Taiwanese Christian pastor and missionary family. He received the B.S. degree from National Cheng Kung University, the M.S. degree from University of Delaware, Newark, and the Ph.D. degree from University of Wisconsin-Madison, in 1978, 1984, and 1987 respectively, all in mechanical engineering.

After two-year military service in King-Men, he worked for San-Yang (Honda) Industry from 1980 to 1981 and Sandvik (Taiwan) from 1981 to 1982 . In 1988, he joined the Department of Electrical and Control Engineering, National Chiao Tung University, as an Associate Professor and was promoted to Professor in 1995. Since 1998, he served as the Chairman of the department. His research interests include mechantronics, motion control, and fault diagnostic systems. 